\title{
2D Upper Bound Analysis of ECAE through 20-Dies for a Range of Channel Angles
}

\author{
Alexander V. Perig* \\ Department of Industrial Automation, Donbass State Engineering Academy, \\ Shkadinova Str., 72, Kramatorsk, Ukraine, 84313
}

Received: January 28, 2014; Revised: September 17, 2014

\begin{abstract}
Equal Channel Angular Extrusion (ECAE), sometimes referred to as Equal Channel Angular Pressing (ECAP), is a Severe Plastic Deformation technique. However the energy-power parameters of ECAE have not been fully addressed in previous known publications. The present article is focused on the punching pressure, accumulated plastic strain, and dead metal zone geometry estimation during ECAE of metal workpieces through a $2 \theta$-die with a channel intersection angle of $2 \theta>0^{\circ}$ and $2 \theta \neq 90^{\circ}$. Computational analytical results for ECAE technological parameters have been analytically derived for planar flow of a plastic, incompressible, non-hardening metal workpiece in an angular Segal die with $2 \theta>0^{\circ}$ and $2 \theta \neq 90^{\circ}$. This is accomplished through the use of an Upper Bound Method (UBM) with Discontinuous Velocity Field (DVF) introduction. The development of the Dead Zone (DZ) for metal ECAE through a $2 \theta$-die with $2 \theta>0^{\circ}$ and $2 \theta \neq 90^{\circ}$ has been analytically investigated. The obtained computational results for $2 \theta$-die have been compared with the slip line analytic solutions of Segal for non-rectangular $2 \theta$-dies of the same geometry. Good agreement between the two computational results has been found. The physical modeling techniques using plasticine have confirmed the appearance of a dead zone and material flow dynamics during ECAE through the Segal 20-die.
\end{abstract}

Keywords: ECAE, Upper Bound Method, Discontinuous Velocity Field, dead zone, strain, marker, gridline, plasticine

\section{Introduction}

The manufacture of new advanced materials requires the development of new material forming deformation techniques. Equal Channel Angular Extrusion (ECAE), also known as Equal Channel Angular Pressing (ECAP), is one of the prominent Severe Plastic Deformation (SPD) techniques ${ }^{1-32}$. ECAE involves one or more extrusion passes of a lubricated billet through a die with two intersecting channels of equal cross-section. This process has been very promising for the production of bulk ultra fine-grained materials with special properties ${ }^{7,17}$. The large cumulative shear strain in ECAE leads to refinement of grains and increased boundary length. The resulting materials show a combination of a very high strength and ductility ${ }^{7,17}$.

The mechanics of Equal Channel Angular Extrusion (ECAE) attracts a lot of research efforts from different fields of theoretical, experimental and industrial science ${ }^{1-32}$. Many contributions have been focused on the introduction of slip line fields ${ }^{11,30,31}$, Upper Bound Method (UBM) with continuous trial velocity fields ${ }^{1-6,12-19,29,32}$, Navier-Stokes equations $^{22,27,28}$, fractal geometry techniques, discrete elements, FEM computational methods ${ }^{2,12,14,15,20,23-25}$ etc.

The main computational approach $\mathrm{in}^{3-5}$ has been grounded on the introduction of cylindrical coordinate systems with the center a symmetrical plastic deformation zone, deriving a kinematically admissible velocity field, computation of the only non-zero strain rate field component $d\left(\varepsilon_{r \theta}\right) / d t$, generation of an equation for dissipated power

*e-mail: olexander.perig@gmail.com balance and further minimization of the expression for dissipated power by optimization parameter differentiation. Laptev et al., 2014 have applied a one-parameter UBM (i.e. UBM for 1 DOF) with a trial DVF to the study of ECAE of an ideally plastic and strain-hardening metal workpiece through a die with channel intersection angle $2 \theta=90^{\circ}$, where the optimization parameter is the dead zone height ${ }^{11}$. Perig et al., 2009 and Perig et al., 2014 have applied a twoparameter UBM (i.e. UBM for 2 DOFs) with a trial DVF to the study of ECAE of an ideally plastic metal workpiece through a die with channel intersection angle $2 \theta=90^{\circ}$, where optimization parameters are the dead zone height and the length of the intermediate bottleneck within dead zone z $^{21,26}$. Perig et al., 2008 have applied a FEM simulation for a numerical description of copper workpiece flow through a $2 \theta$-die ${ }^{[20]}$. Perig et al., 2010 have applied the Navier-Stokes equations in the curl transfer form for the numeric finitedifference description of viscous material flow through an ECAE die with channel intersection angle $2 \theta=90^{\circ[22]}$. Perig et al. have applied a QForm FEM simulation for the numerical description of copper workpiece flow through a die with channel intersection angle $2 \theta=90^{\circ}$, where external die wall is made in the shape of a hyperbola, parabola and catenary curve ${ }^{23}$. Perig et al. have applied a QForm FEM simulation for the numerical description of copper workpiece flow through a die with channel intersection angle $2 \theta=90^{\circ}$, with external and internal radii in the channel intersection zone ${ }^{24}$. Perig et al. have applied physical and numerical simulation techniques to derive the technological 
recommendation concerning rationalization of ECAE of workpieces through $2 \theta$-dies with $2 \theta<90^{\circ}$ by a change of the classical punch shape ${ }^{25}$. Perig et al. have applied the NavierStokes equations in the curl transfer form for a numerical finite-difference description of viscous material ECAE flow through an S-shaped multiple angle die with movable inlet wall ${ }^{27}$. Perig et al. have applied the Navier-Stokes equations in the curl transfer form for the numeric finite-difference description of viscous material flow through an ECAE die with channel intersection angle $2 \theta=90^{\circ}$ and with parallel slants in the channel intersection zone, where the slant width is equal to the inlet and outlet channel widths ${ }^{28}$.

The rigid blocks approach to the UBM of metal flow in ECAE through a $2 \theta$-die with a trial Discontinuous Velocity Field (DVF) has not been addressed, however, in previous known publications ${ }^{1-32}$.

All previous research ${ }^{1-32}$ has not fully addressed the mechanics of ECAE through a $2 \theta$-die with channel intersection angle $2 \theta>0^{\circ}$ and $2 \theta \neq 90^{\circ}$ with an introduction of UBM with trial DVF. This insufficient analysis of energy-power parameters during ECAE through $2 \theta$-die was the stimulus that led to the research reported in the present article, which is the first upper bound approach to workpiece 2D plastic flow through the application of the UBM with DVF.

\section{Physical Simulation of ECAE Through 20-Segal Die}

Plasticine based physical simulation experiments in Figures 1a, c, 9 and 10 are the new original experimental results, obtained personally by the author. The initial plasticine physical models of the workpiece in Figures $1 \mathrm{a}, \mathrm{c}$ and 10 were made from navy blue plasticine in Figure 1a and light blue plasticine in Figures 1c and 10 in the shapes of rectangular parallelepipeds. These rectangular parallelepipeds were frozen, the front sides of parallelepipeds were marked, and through-holes in parallelepipeds were perforated. After that the plasticine parallelepipeds with through-holes were frozen again. Simultaneously the plasticine pieces with different colors were heated to the half-solid state and were placed into through-holes of parallelepipeds through the application of squirt without needle. In this way the initial circular plasticine gridline was formed within the plasticine model of the workpiece. Simple new original physical simulation experiments of workpiece model flow during ECAE through a $2 \theta$-die with the channel width $a=27 \mathrm{~mm}$ and the channel intersection angle $2 \theta=105^{\circ}$ are shown in Figures 1,9 and 10. The ECAE die model is manufactured from kapron in Figure 1a and wood in Figures 1c and 10, and the front

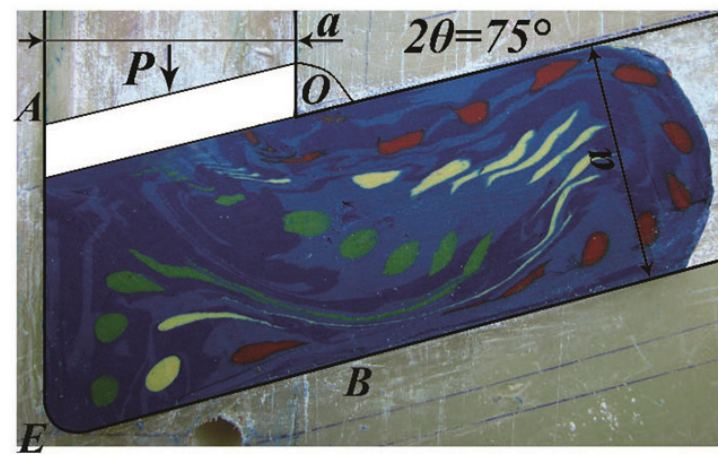

(a)

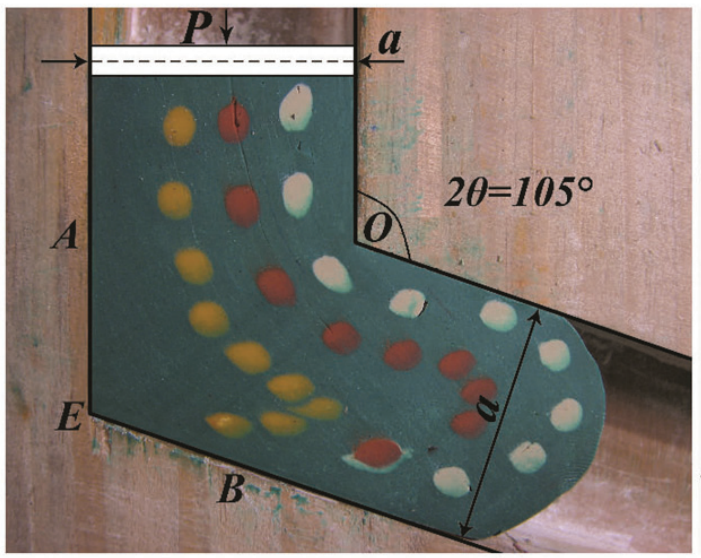

(c)

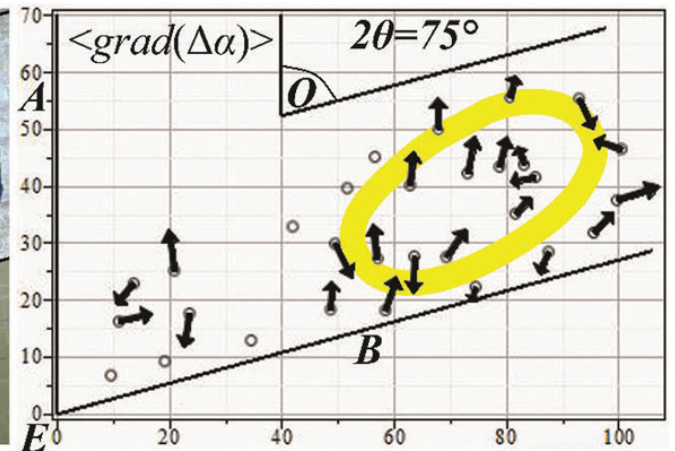

(b)

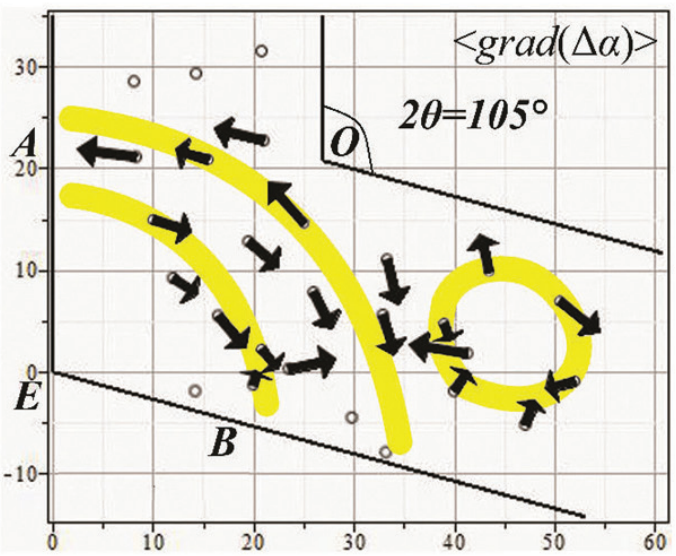

(d)

Figure 1. Physical simulation of ECAE through non-rectangular $2 \theta$-dies with channel intersection angles $2 \theta=75^{\circ}(a, b)$ and $2 \theta=105^{\circ}$ $(c, d)$ showing dead zones $A E B$ formation as well as the formation of material macroscopic rotation in outlet channels $O E B$ ( $a, c)$; and experimental vector fields of macroscopic rotation gradients $(b, d)$. 
face of each ECAE die model is manufactured with glassy plexiglass. In Figures 1a, c and 10 are outlined the plasticine physical models with circular plasticine gridlines.

The applied punching force in Figure 1 is marked as $P$, the applied punching pressure in Figures 3, 4, 6a and (1)-(2) is marked as $p$, and the direction of $P$ and $p$ defines the processed workpiece model flow direction sequentially from the top along the inlet channel $A O E$ of $2 \theta$-die (from $A O$ to $E B$ ) to the right and down along the outlet channel $O E B$ (from $A E$ to $O B$ ). It has been found experimentally that in the external corner $A E B$ of $2 \theta$-die the dead zone $A E B$ of plastic material flow appears. As follows from Figures 1a, c and 10 with circular gridlines shown, in the neighborhood of the outlet $2 \theta$-die channel $O E B$, deformed elliptical markers indicate two independent types of Severe Plastic Deformations (SPD).

The first material deformation results in unevenness of the workpiece plastic flow in the outlet die channel $O E B$ and is associated with the relative rotation of the major axes for every deformed elliptical marker with respect to axis $E B$. This relative rotation of elliptical markers as rigid solids takes place for every marker in outlet $2 \theta$-die channel $O E B$ and indicates processed workpiece material macroscopic rotation. The closed loops of macroscopic rotation, located in the outlet channels of the ECAE dies, are shown in Figures $1 b, d$. Another type of material deformation is associated with relative bending of elliptical markers and the appearance of inflection points for every marker. This type of deformation is defined as rotational inhomogeneity.

\section{Upper Bound Analysis of ECAE Through 20-Segal Die}

The upper bound theorem equation according to the works ${ }^{8,9}$ has the following form:

$\left(\frac{d E}{d t}\right)_{\text {Johnson- Kudo }}=\left(k \sum l_{i j} \Delta u_{i j}^{\prime}\right)_{\text {Johnson-Kudo }}+\left(\sum f_{k} l_{k} \Delta u_{k}^{\prime}\right)_{\text {Johnson- Kudo }}$ where $(\mathrm{d} E / \mathrm{d} t)_{\text {Johnson-Kudo }}$ is defined in ${ }^{8,9}$ as "the total rate of energy dissipation in the system per unit thickness in the direction normal to the plane of flow"; multiplier (k)

is defined in ${ }^{8,9}$ as "the shear stress"; $\left(l_{i j}\right)_{\text {Johnson-Kudo }}$ and $\left(\Delta u_{i j}^{\prime}\right)_{\text {Johnson-Kudo }}$ are defined in ${ }^{8,9}$ as "the length of a straight boundary and the rate of relative slip between triangles " $i$ " and " $j$ " respectively"; $\left(f_{k}\right)_{\text {Johnson-Kudo }},\left(l_{k}\right)_{\text {Johnson-Kudo }}$ and $\left(\Delta u_{k}^{\prime}\right)_{\text {Johnson-Kudo }}$ with subscript $\mathrm{k}$ are defined in ${ }^{8,9}$ as "the frictional resistance, the length of contact and the rate of relative slip between triangle $\mathrm{k}$ and the contacting tool surface" (Johnson \& Kudo, 1962) ) $^{8,9}$.

According to the UBM (Figure $2 \mathrm{a}$ ) a trial velocity field (Figure $2 \mathrm{~b}$ ) for a $2 \theta$-die has to be introduced.

The trial velocity field can be continuous, discontinuous or mixed. In the present work a discontinuous velocity

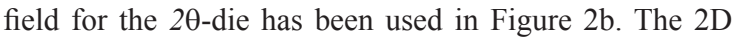
plane model of the metal workpiece in the $2 \theta$-die has been divided into 4 rigid triangular sections $A O C$ (number 1 ), $O C D$ (number 2), $O D B$ (number 3), and $C D E$ (number 4), as shown in Figure 2a. The appearance of a symmetrical dead metal zone $C D E$ in the shape of the rigid triangular block $C D E$ numbered 4, which is adjacent to the die external angle $E$, lies within both inlet $A O E$ and outlet $E O B$ die channels (Figure 2a) and has the assumed height $h=a x$, where $a$ is the channel width, and $0 \leq x \leq \cot (\theta)$. It is necessary to note that an assumption concerning the formation of an asymmetrical dead zone $C D E$ (number 4) for metal ECAE through a $2 \theta$-die is completely unacceptable because possible asymmetry of dead zone $C D E$ (number 4 ) would result in a violation of metal incompressibility for the rigid blocks division used in Figure 2a.

We also will suppose that ECAE occurs with no backpressure and the constant plastic friction between the workpiece and $2 \theta$-die walls is independent of the normal stress $\sigma_{n}$ and is acting only for inlet $l_{A C}$ and outlet $l_{D B}$ lengths. The friction stress $\tau_{f}$ we will define according to the Siebel (Tresca) friction law as $\tau_{f}=m k$, where $0 \leq m \leq 1$ is the

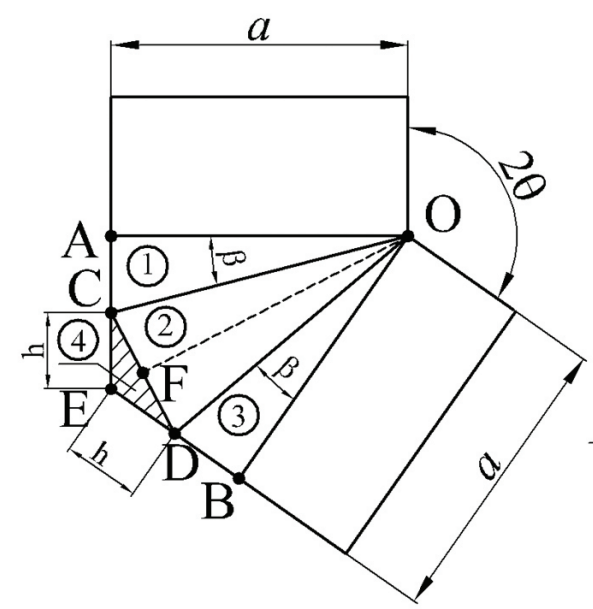

(a)

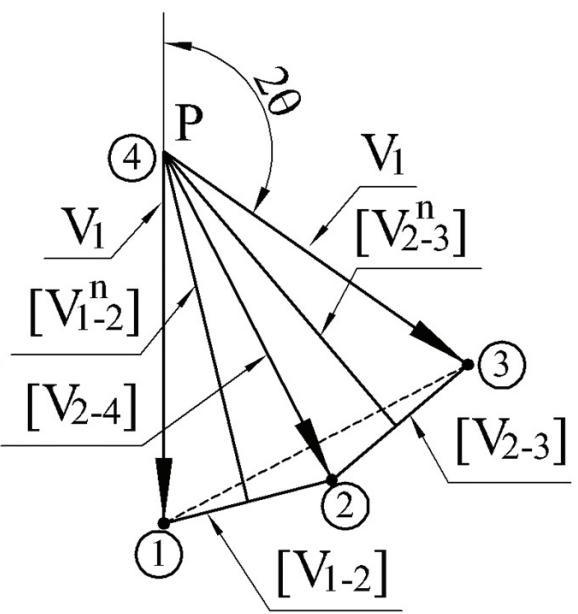

(b)

Figure 2. The rigid blocks partitioning scheme of ECAE through a non-rectangular Segal $2 \theta$-die $(a)$ and corresponding velocity hodograph (b). 
plastic friction factor in the Siebel (Tresca) friction law, the shear strength of the extruded material $k=\sigma_{S} / \sqrt{3}$ is the plastic constant, i.e. $k$ is the maximum tangential stress for material with flow stress $\sigma_{S}$.

We will calculate punching pressure $p$ at the entrance line $A O$. Corresponding to the partitioning scheme for Segal $2 \theta$-die in Figure 2a, a velocity hodograph has been shown in Figure $2 \mathrm{~b}$. The extruded workpiece material we will assume as rigid-plastic with no strain-hardening. The plastic friction force has been assumed as independent of sliding velocity.

The balance of external and internal power of plastic deformation for ECAE of the rigid-plastic and nonhardening workpiece material in (1) is expressed by the following algebraic equation (Figures 3, 4 and 6a):

$p \cdot a \cdot V_{1}=k \cdot\left(l_{1-2} \cdot\left[V_{1-2}\right]+l_{2-3} \cdot\left[V_{2-3}\right]+l_{2-4} \cdot\left[V_{2-4}\right]\right)+$

$2 m k \cdot(a \cdot \cot (\theta)-h) \cdot V_{1}$ where $p$ is an applied ECAE punching pressure; $l_{\text {i- }-1}$ are the lengths of common boundaries or interface joints for rigid blocks $i$ and $j$ within the $2 \theta$-die rigid blocks partitioning scheme (Table 1$) ; l_{\mathrm{AC}}=l_{\mathrm{DB}}$ are the lengths of friction zones; $\left[V_{\mathrm{i}-\mathrm{j}}\right]$ are the velocities of relative sliding for blocks $i$ and $j ; i, j=1,2,3$ (Table 1 ); $V_{1}$ and $V_{3}$ are material velocities in the inlet $A O E$ and outlet $O E B 2 \theta$-die channels respectively. Moreover, due to the ECAE process symmetry requirement we have the following identities: $V_{1}=V_{3}$ and $2 m k \cdot(a \cdot \cot (\theta)-h) \cdot V_{1}=m k \cdot\left(l_{A C} V_{1}+l_{D B} V_{3}\right)$.

The terms in Equation 2 have been expressed as the functions of pressing velocity $V_{1}$ and the relative length of the symmetric dead zone $x=h / a$ in Table 1 . After substitution of obtained relationships from Table 1 in Equation 2 and algebraic transformation, the following elementary formula for calculation of relative ECAE punching pressure has been derived (Figures 3, 4 and 6a):

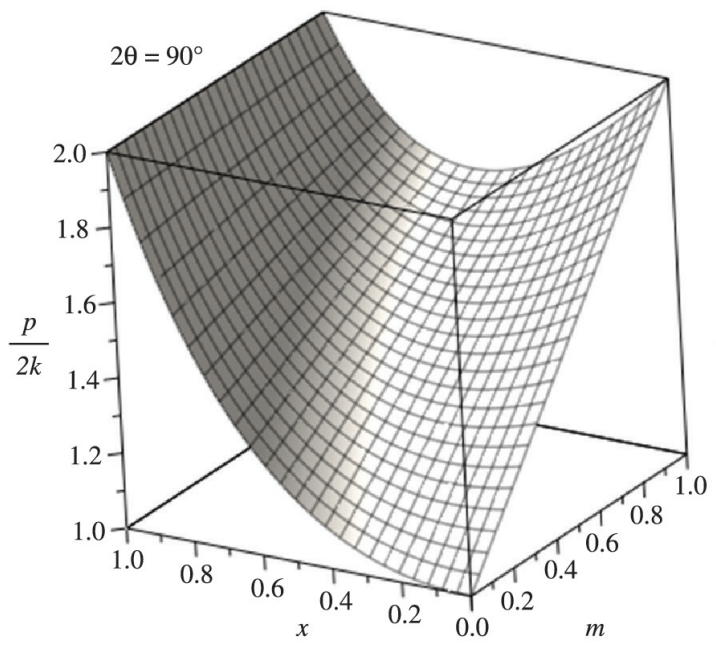

(a)

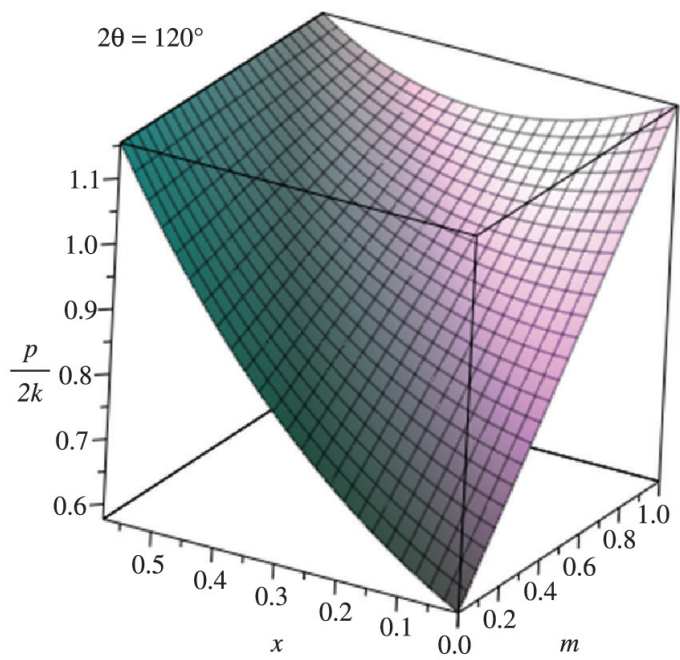

(c)

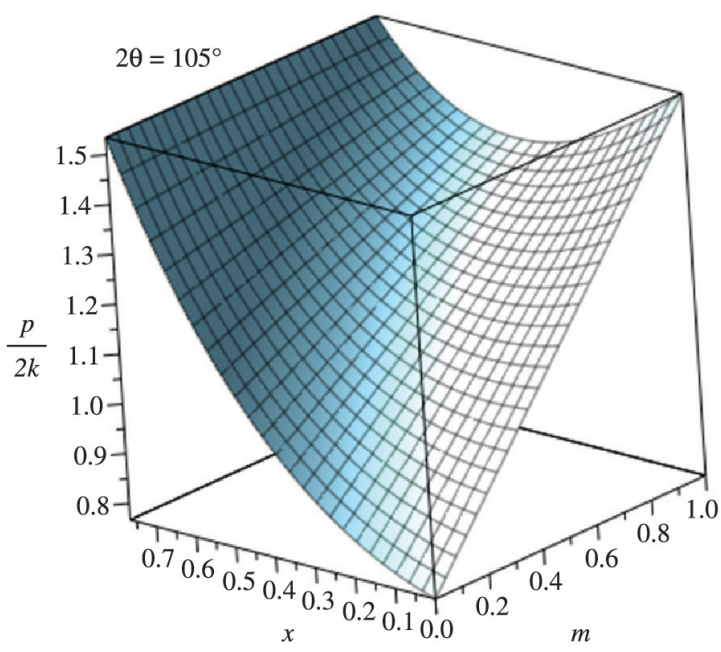

(b)

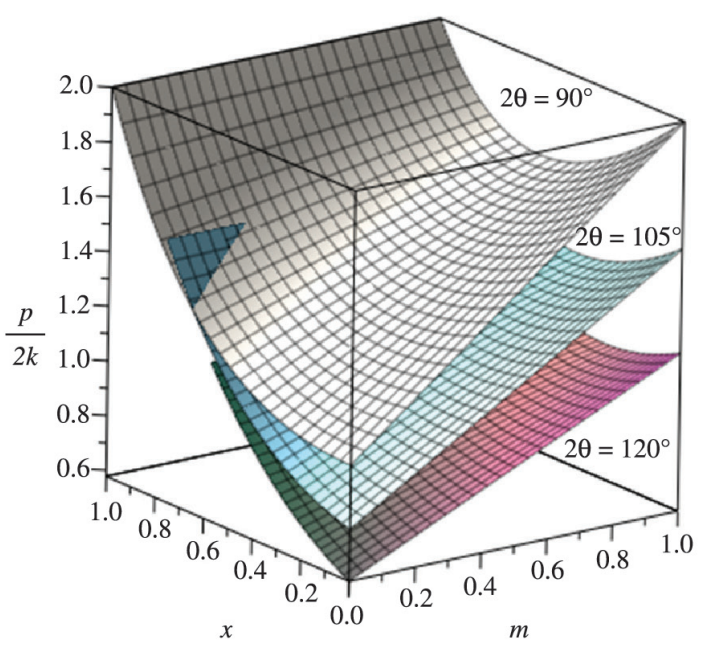

(d)

Figure 3. Spatial surface graphs $(d)$ for relative ECAE punching pressure $p / 2 k$ versus dead zone relative length $x$ and friction factor $m$ for Segal $2 \theta$-dies with channels intersection angles $2 \theta=90^{\circ}$ (surface of Floral White color in $a, d$ ), $2 \theta=105^{\circ}$ (surface of Sky Blue color in $b, d$ ), and $2 \theta=120^{\circ}$ (colored surface in $c, d$ ). 
Table 1. The lines of discontinuity and sliding velocities for a $2 \theta$-Segal die.

\begin{tabular}{cccc}
\hline Velocity discontinuity lines $\boldsymbol{i}-\boldsymbol{j}$ & \multicolumn{1}{c}{$\boldsymbol{l}_{\boldsymbol{i}-\boldsymbol{j}}$} & {$\left[\boldsymbol{V}_{i-j} \mathrm{I}\right.$} & $\boldsymbol{V}_{\boldsymbol{i}-\boldsymbol{j}}^{\boldsymbol{n}}$ \\
\hline $1-2$ & $a \sqrt{1+(\cot (\theta)-x)^{2}}$ & $\frac{V_{1} \cdot \sqrt{1+(\cot (\theta)-x)^{2}}}{(\tan (\theta)+(\cot (\theta)-x))}$ & $\frac{V_{1}}{\sqrt{1+(\cot (\theta)-x)^{2}}}$ \\
$2-3$ & $a \sqrt{1+(\cot (\theta)-x)^{2}}$ & $\frac{V_{1} \cdot \sqrt{1+(\cot (\theta)-x)^{2}}}{(\tan (\theta)+(\cot (\theta)-x))}$ & $\frac{V_{1}}{\sqrt{1+(\cot (\theta)-x)^{2}}}$ \\
$2-4$ & $\frac{V_{1}}{\cos (\theta) \cdot(\tan (\theta)+(\cot (\theta)-x))}$ & 0 \\
\hline
\end{tabular}

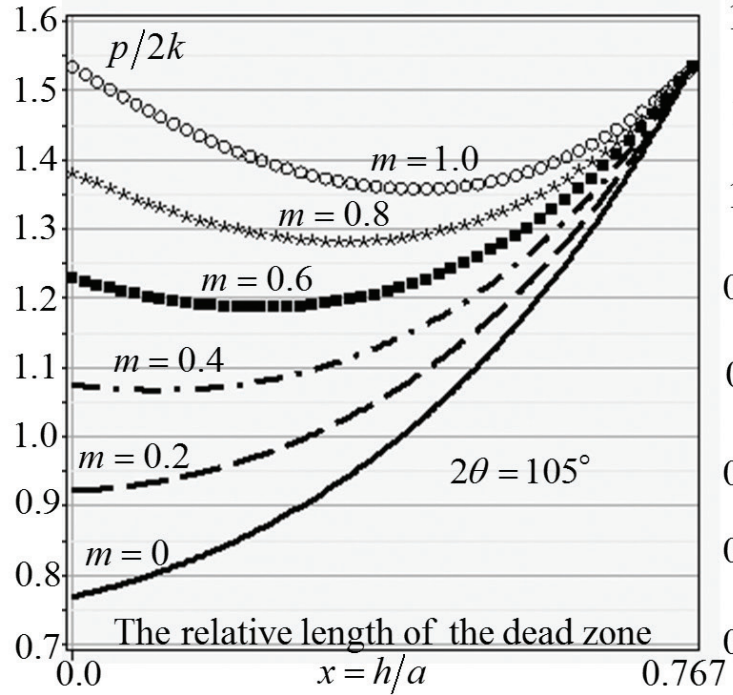

(a)

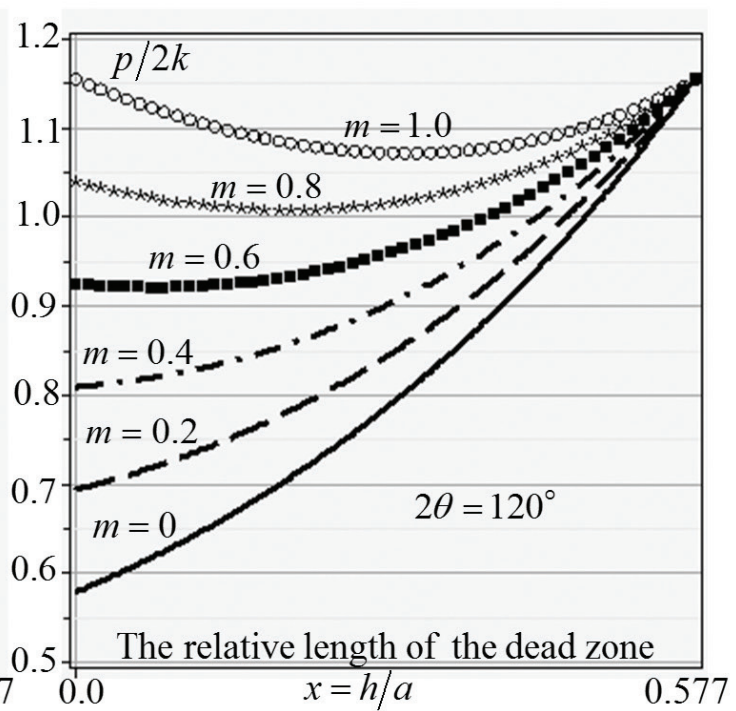

(b)

Figure 4. Dependences of relative punching pressure $p / 2 k$ with respect to $x=h / a$ for workpieces ECAE through Segal $2 \theta$-dies with channel intersection angles $2 \theta=105^{\circ}(a)$ and $2 \theta=120^{\circ}(b)$ for the following friction factor $m$ values: $\longrightarrow(m=0),-\longrightarrow(m=0.2)$,

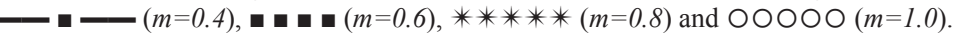

$\left(\frac{p}{2 k}\right)=\left(\frac{\left(1+x \cdot \tan (\theta)+(\cot (\theta)-x)^{2}\right)}{(\tan (\theta)+(\cot (\theta)-x))}\right)+m \cdot(\cot (\theta)-x)$

Calculations from Equation 3 are shown in Figures 3, 4 and $6 a$.

The correctness of derived algebraic expression (3) may be confirmed by substituting $\theta=45^{\circ}$ in (3). This case corresponds to ECAE of metal through a die with channel intersection angle $2 \theta=90^{\circ}$, studied in the work ${ }^{11}$ of Laptev et al. In this case the derived Formula 3 coincides with expression (3) of the work in ${ }^{11}$.

According to the UBM the best approximation of the real punching pressure $p / 2 k$ through $2 \theta$-die of Segal corresponds to the minimum of Expression 3, i.e. requires the solution of equation $\partial(p / 2 k) / \partial x=0$. The analytic algebraic analysis of (3) shows that the minimum of this function for ECAE punching pressure $(p / 2 k)$ takes place when the relative height has the value

$$
x=\left[\frac{(1+m)\left(1+\tan ^{2}(\theta)\right)-\tan (\theta) \cdot \sqrt{2 \cdot(1+m) \cdot\left(1+\tan ^{2}(\theta)\right)}}{[(1+m) \cdot \tan (\theta)]}\right]
$$

The derived general analytic Formula 4 coincides with algebraic expression (4) of the work ${ }^{11}$ in the case of ECAE through a die with channel intersection angle $2 \theta=90^{\circ}$.

Using Equations 3 and 4 we may estimate the relative height $x$ of dead zone $C D E$ (number 4 in Figure 2a) and the value $p / 2 k$ of the relative punching pressure during ECAE through a Segal $2 \theta$-die. It has been found from Equation 4 that in some cases the global minimum of relative punching pressure $p / 2 k$ during ECAE through a $2 \theta$-die is not reached at positive values of relative length $x$ of dead zone $C D E$ in Figure 1a. This means that the dead zone $C D E$ does not always appear during ECAE through $2 \theta$-die. The development of a dead zone $C D E$ can be seen in Figure 5. 
Plotted curve families in Figure 5 have been derived on the basis of (4) with the limitation for $x=h / a$ that $0 \leq x \leq \cot (\theta)$.

In Figure 5 the graphical dependencies have been shown for the relative height of dead zone $C D E$ with respect to friction factor $m$ for different $2 \theta$-die angles, which have been

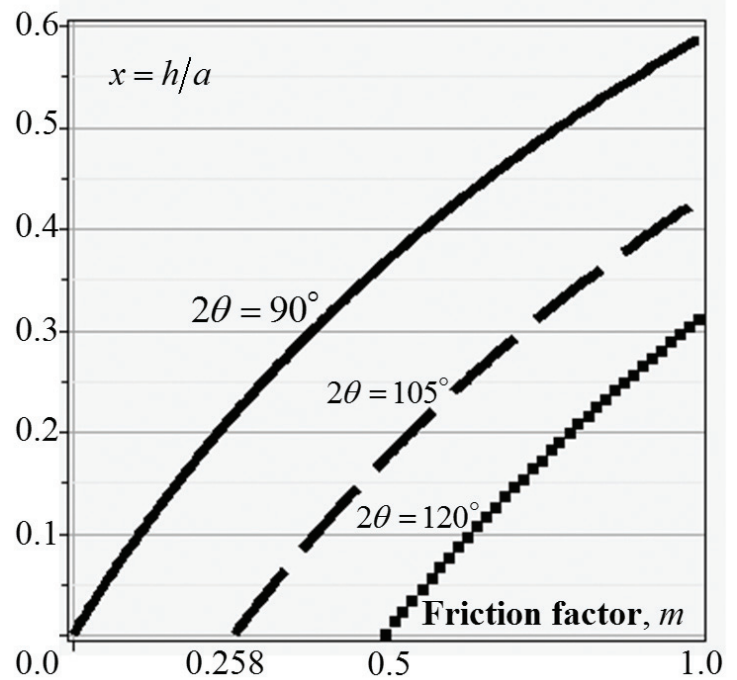

Figure 5. The character of the influence of friction factor $m$ and the angle $2 \theta$ between the channels of the Segal angular die on the formation and the relative height $x=h / a$ of dead zone $C D E$ during ECAE: $\left(2 \theta=90^{\circ}\right),--\left(2 \theta=105^{\circ}\right)$, and प प $\left(2 \theta=120^{\circ}\right)$. For die angle $2 \theta=90^{\circ}$ we have $x \geq 0$ for $0 \leq m \leq 1.0$; for $2 \theta=105^{\circ}$ we have $x \geq 0$ for $0.258 \leq m \leq 1.0$; and for $2 \theta=120^{\circ}$ we have $x \geq 0$ for $0.5 \leq m \leq 1.0$. derived with UBM according to the Formula 4 for $x=h / a$. So the dead zone $C D E$ (Figure $2 \mathrm{a}$ ) of plastic flow always appears in the case of non-zero friction factor $m \neq 0$ for ECAE through a Segal die with channel intersection angle $2 \theta=90^{\circ}$. However, in the case of ECAE through the Segal die with channel intersection angle $2 \theta=105^{\circ}$ the dead zone $C D E$ (Figure 2a) forms and appears only for the friction factor values $m \geq 0.258$ (Figure 5). During ECAE through the die with $2 \theta=120^{\circ}$ the dead zone $C D E$ (Figure 2a) appears only for the friction factor values $m \geq 0.5$ (Figure 5).

ECAE is a SPD technique for grain refinement. Therefore the estimation of resulting plastic ECAE shear is also important. The total ECAE shear $\gamma_{S}$ (Figure 6b) is the sum of the shears on the discontinuity inclined lines $C O$ and $D O$ in Figure 2a, i.e.

$$
\gamma_{S}=\gamma_{1-2}+\gamma_{2-3}=2 \gamma
$$

The meaning and the correction of linear superposition of finite deformations in (5) is shown in Figures 7, 8 and Table 2 through the good agreement of (5) with the slip line analysis results. The comprehensive background for linear superposition of finite deformations in (5) was made by Johnson \& $\mathrm{Kudo}^{8}$, Kudo ${ }^{9}$, and Laptev et. al. ${ }^{10,11}$.

It is known that

$$
\gamma=\gamma_{i-j}=\left[V_{i-j}\right] / V_{i-j}^{n}
$$

where $V_{i-j}^{n}$ is a velocity component orthogonal to a discontinuity line $l_{\mathrm{i}-\mathrm{j}}$ (Table 1 ).

Using (6) and Table 1 we will calculate $\gamma$ with the following expression:

$$
\gamma=\gamma_{1-2}=\gamma_{2-3}=\left(1+(\cot (\theta)-x)^{2}\right) /(\tan (\theta)+(\cot (\theta)-x))
$$

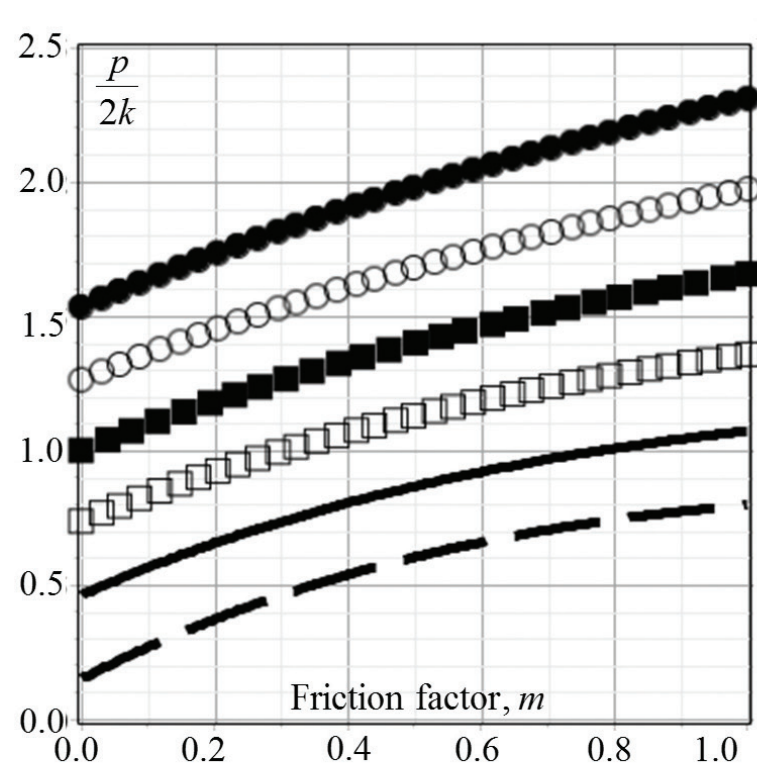

(a)

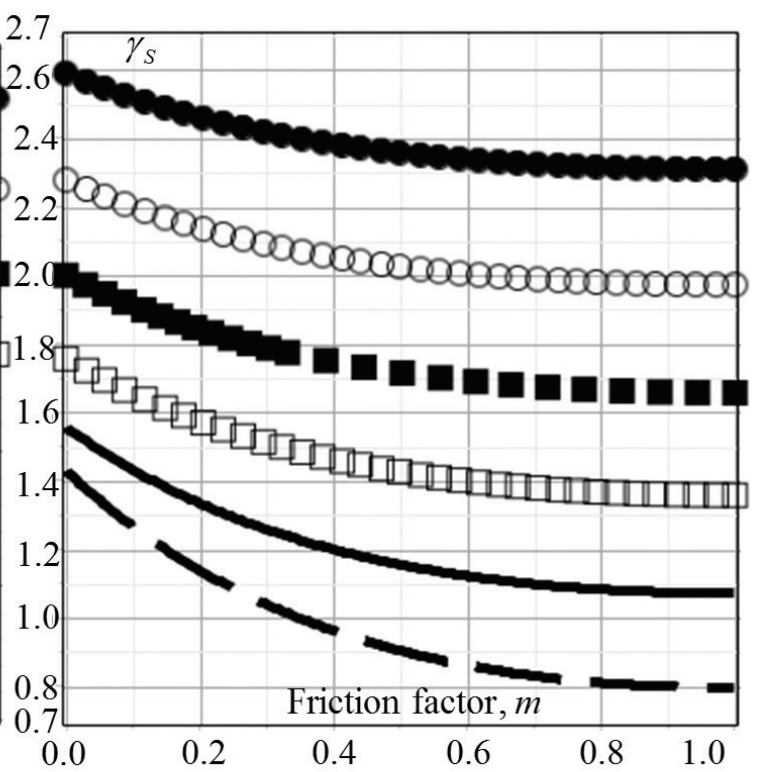

(b)

Figure 6. Dependences of relative punching pressure $p / 2 k(a)$ and summary plastic shear $\gamma_{\mathrm{S}}(b)$ with respect to the friction factor $m$, derived

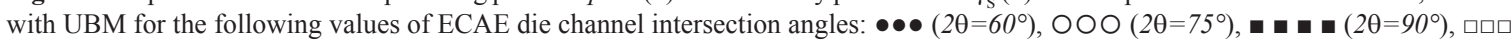
$\left(2 \theta=105^{\circ}\right), \longrightarrow\left(2 \theta=120^{\circ}\right)$, and $\longrightarrow\left(2 \theta=135^{\circ}\right)$. 


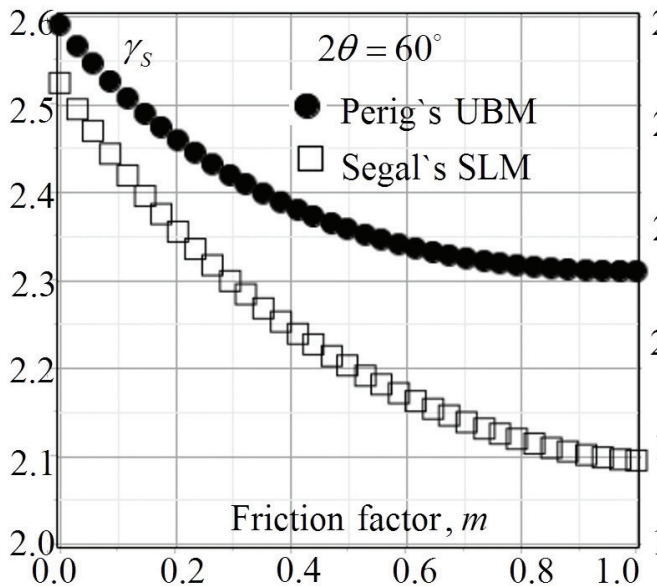

(a)

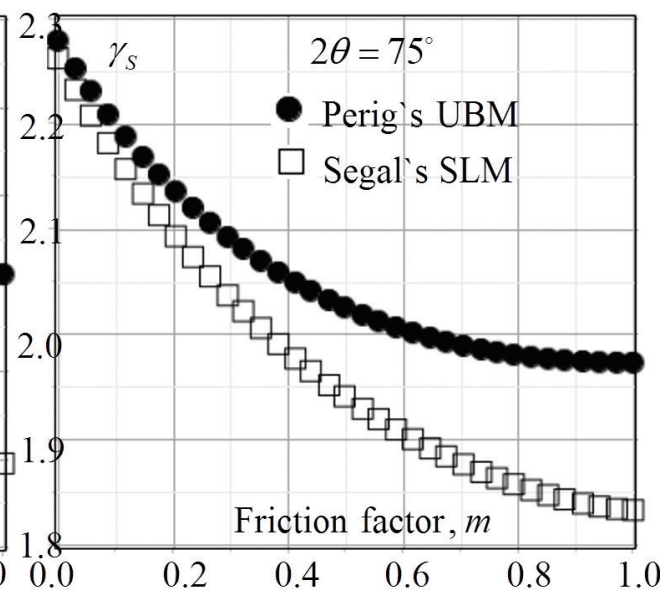

(b)

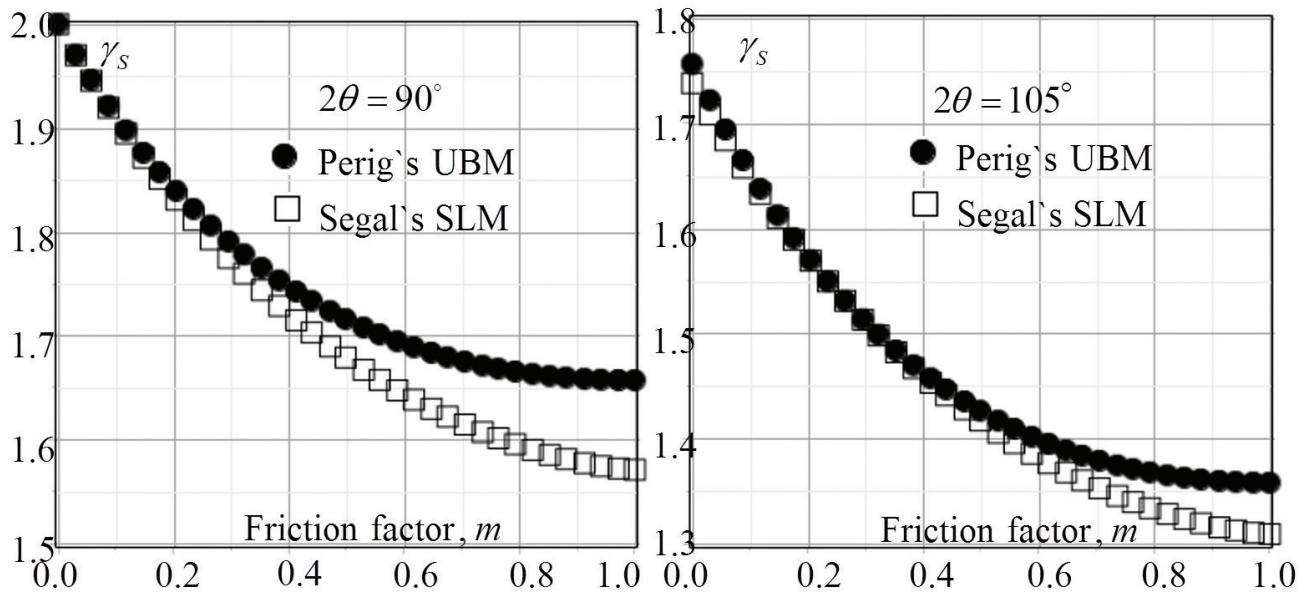

(c)

(d)

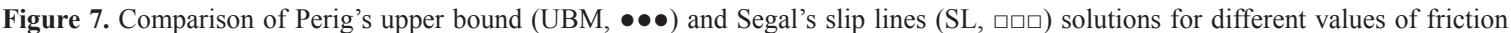
factor $m$. Computational dependencies for summary plastic shear $\gamma_{\mathrm{S}}(a-d)$ with respect to the friction factor $m$, derived with UBM and slip line method (SLM) during ECAE of non-hardening material through Segal dies with channel intersection angles $2 \theta=60^{\circ}(a), 2 \theta=75^{\circ}$ (b), $2 \theta=90^{\circ}(c)$, and $2 \theta=105^{\circ}(d)$.

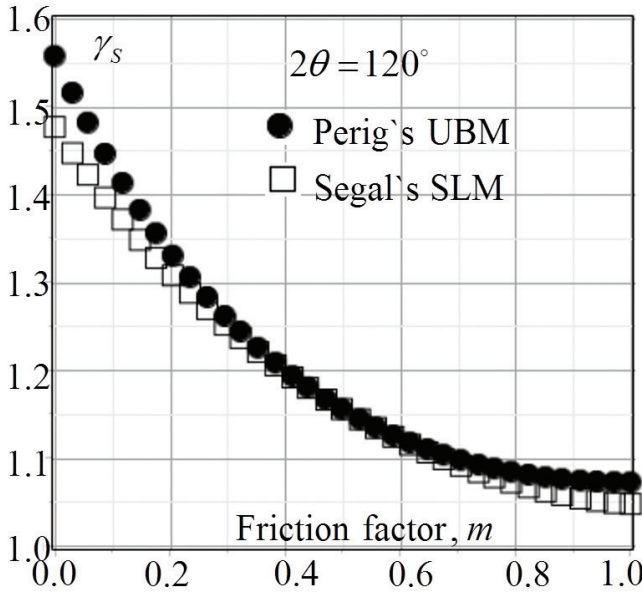

(a)

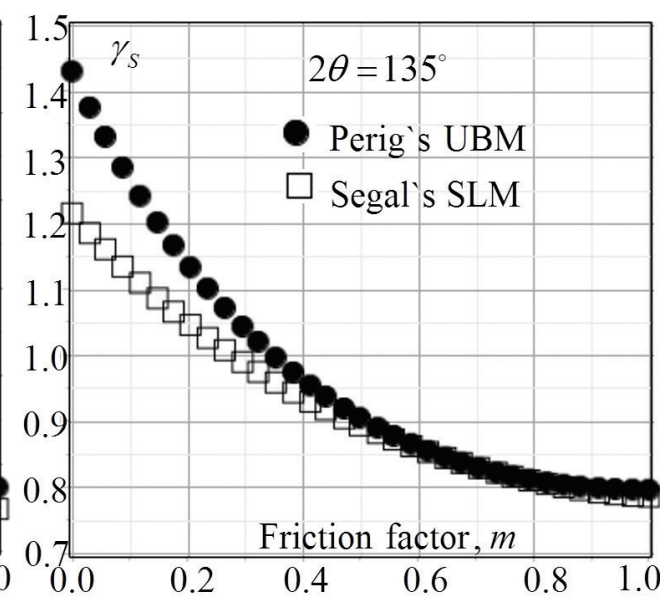

(b)

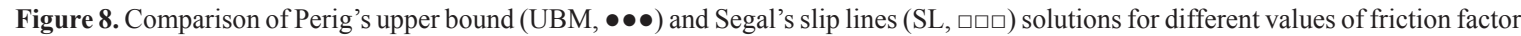
$m$. Computational dependencies for summary plastic shear $\gamma_{\mathrm{S}}(a, b)$ with respect to the friction factor $m$, derived with UBM and slip line method (SLM) during ECAE of non-hardening material through Segal dies with channel intersection angles $2 \theta=120^{\circ}(a)$ and $2 \theta=135^{\circ}(b)$. 
Table 2. Comparison of total plastic shears, derived by Perig's upper bound and Segal's slip lines solutions for different values of friction factor $m$.

\begin{tabular}{|c|c|c|c|c|c|}
\hline $2 \theta$ & Figures & $\mathbf{m}$ & $\left.\left(\gamma_{\mathrm{S}}^{\text {max }}\right)_{\text {UBM }}\right|^{\text {Perig }}$ & $\left.\left(\gamma_{S}^{\text {max }}\right)_{\text {SLM }}\right|^{\text {Segal }}$ & $\delta_{\max }$ \\
\hline $60^{\circ}$ & $7 \mathrm{a}$ & 1.0 & 2.309 & 2.094 & $9.788 \%$ \\
\hline $75^{\circ}$ & $7 b$ & 1.0 & 1.972 & 1.832 & $7.368 \%$ \\
\hline $90^{\circ}$ & $7 c$ & 1.0 & 1.657 & 1.571 & $5.337 \%$ \\
\hline $105^{\circ}$ & $7 d$ & 1.0 & 1.358 & 1.309 & $3.662 \%$ \\
\hline $120^{\circ}$ & $8 \mathrm{a}$ & 0.0 & 1.557 & 1.476 & $5.323 \%$ \\
\hline $135^{\circ}$ & $8 b$ & 0.0 & 1.430 & 1.215 & $16.377 \%$ \\
\hline
\end{tabular}

From the hodograph in Figure $1 \mathrm{~b}$ and Table 1, from which

$$
\gamma_{S}=2 \cdot \gamma=2 \cdot\left(1+(\cot (\theta)-x)^{2}\right) /(\tan (\theta)+(\cot (\theta)-x))
$$

The derived general analytic Formula 8 for accumulated plastic shear coincides with algebraic Expression 8 of the work $^{11}$ in the case of ECAE through a die with channel intersection angle $2 \theta^{\circ}=90^{\circ}$.

Then the equivalent plastic strain during ECAE may be calculated as follows:

$$
\varepsilon_{e}=\gamma_{S} / \sqrt{3}=(2 / \sqrt{3}) \cdot\left(1+(\cot (\theta)-x)^{2}\right) /(\tan (\theta)+(\cot (\theta)-x))
$$

The relative area of the dead zone $C D E$ in Figure 2 may be estimated as follows:

$$
\frac{S}{a^{2}}=\frac{1}{2}\left(\frac{h}{a}\right)^{2} \cdot \sin (2 \theta)=\frac{1}{2} x^{2} \cdot \sin (2 \theta)
$$

The derived general analytic formula (10) for relative area of the dead zone coincides with algebraic expression (16) of the work ${ }^{11}$ in the case of ECAE through a die with channel intersection angle $2 \theta=90^{\circ}$.

\section{Discussion of Results for ECAE Through 20-Segal Die}

The results (2)-(10) derived from the UBM have been compared with Segal's Slip Lines (SL) solution for summary shear $\gamma_{\text {Segal }}^{30,31}$ for $\theta>0$.

The relative ECAE pressure $p / 2 k$ corresponding to the slip line analysis Segal has calculated $\mathrm{in}^{30,31}$ by the following analytical formula:

$$
(p / 2 k)_{\text {Segal }}=[\cot \eta+2(\eta-\theta)]+m /[2 \sin \eta \cdot(\sin \eta+\cos \eta)]
$$

where

$$
\eta=\pi / 2-1 / 2 \cdot \arccos (m)
$$

According to $\mathrm{t}^{30,31}$ the summary shear by Segal is as follows:

$\gamma_{\text {Segal }}=2 \cdot \cot \eta+2 \cdot(\eta-\theta)$

The results of the comparison for total plastic shear (8), (4), (12) and (13) have been presented in Figures 7, 8 and Table 2.

As expected, the values of accumulated ECAE plastic shear $\gamma_{\mathrm{S}}$ (Figures 7, 8 and Table 2), obtained by the upper bound analysis (UBM), are higher than corresponding ones derived by the slip line theory (SLM), the differences ranging from negligible to $16.4 \%$. The relative divergence (disagreement) of results was evaluated by the formula:

$\delta=\frac{1}{2}\left(\frac{\left|R_{U B M}-R_{S L M}\right|}{R_{U B M}}+\frac{\left|R_{U B M}-R_{S L M}\right|}{R_{S L M}}\right) \cdot 100 \%$

where $R_{S L M}$ and $R_{U B M}$ are the values obtained by the slip line (SLM) and upper bound (UBM) theories respectively.

The evaluation shows (Figure 7 - Figure 8 and Table 2 ) that for the values of friction factor $0 \leq m \leq 1$ and die channel intersection angle $2 \theta=90^{\circ}$ the maximum divergence of results $\delta_{\max }$ for total shear $\gamma_{\mathrm{S}}$ by two-way calculations is $\delta_{\max }(\gamma) \mid\left(2 \theta=90^{\circ}\right)=5.337 \%$.

For the Segal die with $2 \theta=105^{\circ}$ and friction factor $0 \leq m \leq 1$ the maximum difference $\delta_{\max }$ for total shear $\gamma_{S}$ by two-way calculations is $\delta_{\max }(\gamma) \mid\left(2 \theta=105^{\circ}\right)=3.662 \%$. And for the Segal die with $2 \theta=120^{\circ}$ and friction factor $0 \leq m \leq 1$ the maximum difference $\delta_{\max }$ for total shear $\gamma_{\mathrm{S}}$ by two-way calculations is $\delta_{\max }(\gamma) \mid\left(2 \theta=120^{\circ}\right)=5.323 \%$.

Further increase of friction factor $m$ in Figures 5-8 leads to the rise of the extrusion punching pressure $p / 2 k$ (Figure 6a) and to the remarkable decrease in total plastic shear $\gamma_{S}$ (Figures 6b, 7 and 8).

\section{Dead Zone Analysis}

The geometric analysis of local flow during ECAE allows estimate the dead zone relative area $S / a^{2}$ using UBM (10) and physical simulation techniques (Figures 9 and 10).

UBM Formulae 4 and 10 for the die with $2 \theta=105^{\circ}$ and maximum friction factor $m=1.0$ yield the following values $(x)_{\mathrm{UBM}}=0.428$ and $\left(S / a^{2}\right)_{\mathrm{UBM}}=0.0726$ for dead zone geometry in the case of the plastic flow of non-hardening workpiece material. Averaged physical simulation results for visually observable dead zone area in Figures 9 and 10 for the viscous flow of plasticine workpiece models show that $<S / a^{2}>=0.1382$, i.e. physical simulation dead zone area is in 1.91 times larger than theoretical one, derived with UBM Formulae 4 and 10.

The derived divergence of results for relative dead zone area is based on the different rheological features during flow of metal materials and soft physical models of workpieces 


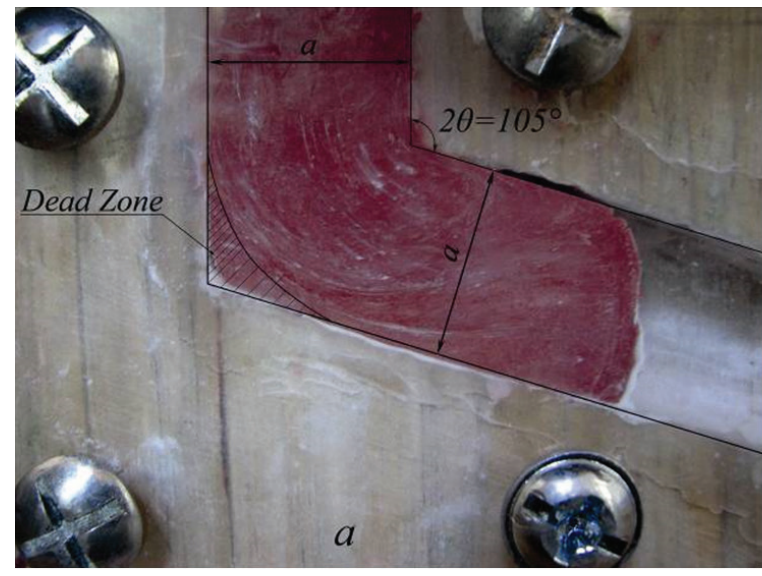

(a)

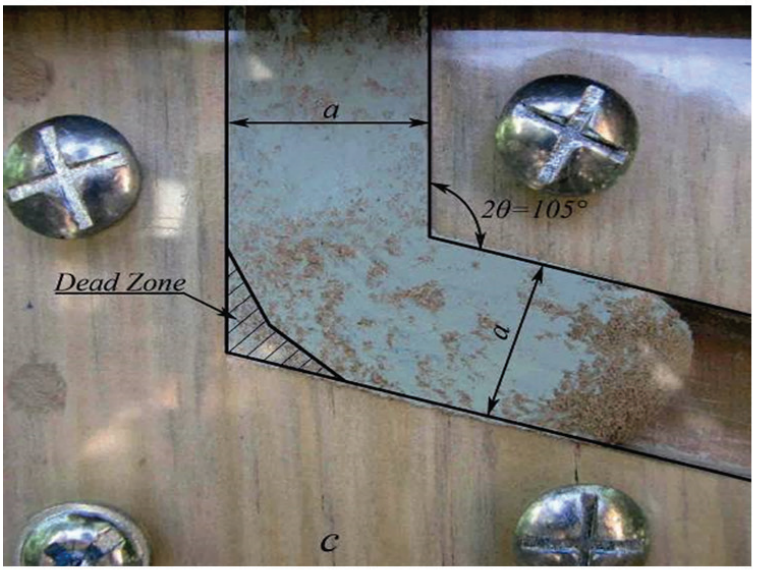

(c)

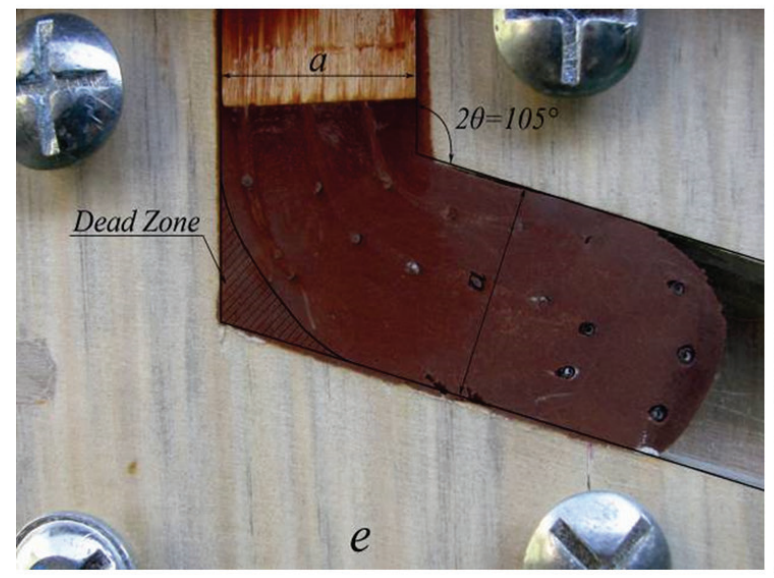

(e)

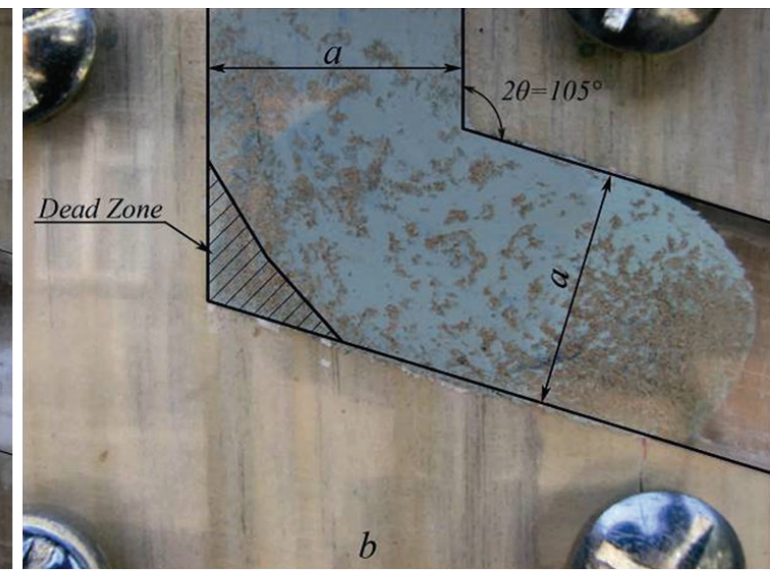

(b)

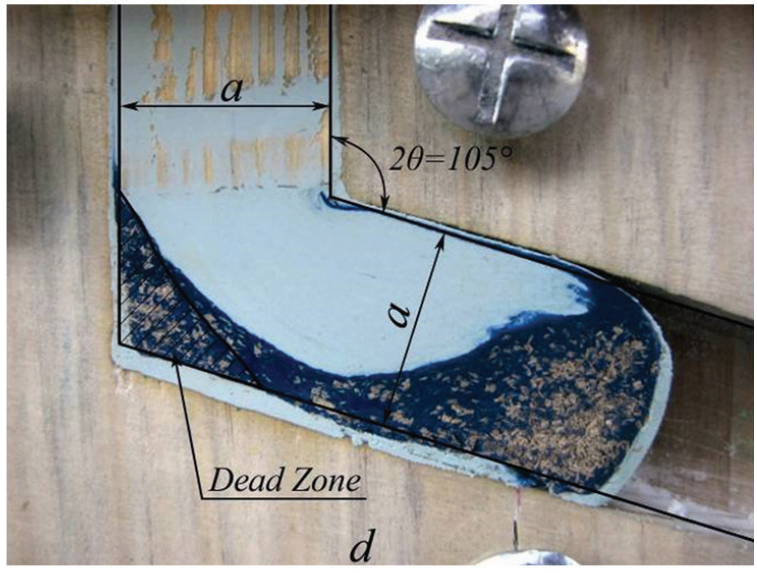

(d)

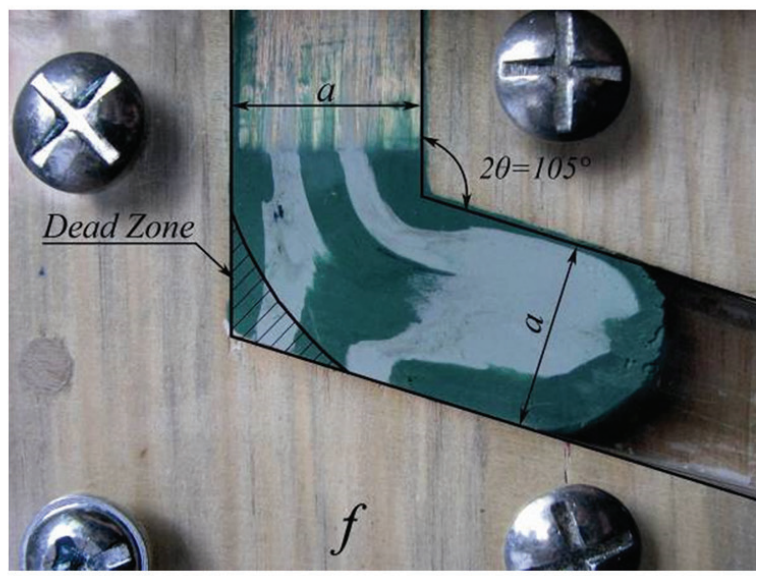

(f)

Figure 9. The physical simulation-derived geometries of observable dead zones during ECAE of plasticine workpieces models through the dies with $2 \theta=105^{\circ}: S / a^{2}=0.1037(a) ; S / a^{2}=0.1267(b) ; S / a^{2}=0.1259(c) ; S / a^{2}=0.2177(d) ; S / a^{2}=0.1016(e) ; S / a^{2}=0.1476(f)$.

through the ECAE die with channel intersection angle $2 \theta=105^{\circ}$ in Figures 9 and 10.

However the derived divergence of results for relative dead zone area does not reduce in any way the importance of physical simulation techniques for quality assessment of
ECAE geometric features during workpiece flow through the $2 \theta$-dies.

\section{Conclusions}

The application of the upper bound theory (UBM) in the form of one-parameter rigid blocks method with trial 


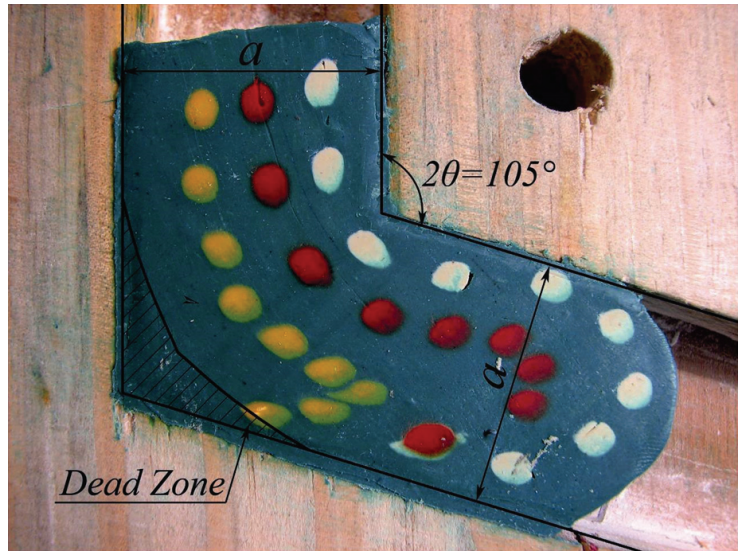

Figure 10. The physical simulation-derived geometry of observable dead zone during ECAE of plasticine workpiece model through the die with $2 \theta=105^{\circ}$, where $S / a^{2}=0.1444$.

discontinuous velocity field to the analysis of ECAE through a Segal $2 \theta$-die correctly describes the essential features for this SPD process like the appearance of a dead zone (DZ) and its increase as a function of external friction.

Physical modeling with circular gridlines and plasticine workpiece models in Figures 1, 9 and 10 confirms the

\section{References}

1. Abrinia K and Mirnia MJ. A new generalized upper-bound solution for the ECAE process. International Journal of Advanced Manufacturing Technology. 2010; 46(1-4):411-421. http://dx.doi.org/10.1007/s00170-009-2103-y.

2. Alkorta J and Sevillano JG. A comparison of FEM and upperbound type analysis of equal-channel angular pressing (ECAP). Journal of Materials Processing Technology. 2003; 141(3):313318. http://dx.doi.org/10.1016/S0924-0136(03)00282-6.

3. Altan BS, Purcek G and Miskioglu I. An upper-bound analysis for equal-channel angular extrusion. Journal of Materials Processing Technology. 2005; 168(1):137-146. http://dx.doi. org/10.1016/j.jmatprotec.2004.11.010.

4. Eivani AR and Karimi Taheri A. An upper bound solution of ECAE process with outer curved corner. Journal of Materials Processing Technology. 2007; 182(1-3):555-563. http://dx.doi. org/10.1016/j.jmatprotec.2006.09.021.

5. Eivani AR and Karimi Taheri A. The effect of dead metal zone formation on strain and extrusion force during equal channel angular extrusion. Computational Materials Science. 2008; 42(1):14-20. http://dx.doi.org/10.1016/j. commatsci.2007.06.001.

6. Faraji G, Abrinia K, Mashhadi M and Hamdi M. An upper-bound analysis for frictionless TCAP process. Archive of Applied Mechanics. 2013; 83(4):483-493.

7. Iwahashi Y, Wang J, Horita Z, Nemoto M and Langton TG. Principle of equal-channel angular pressing for the processing of ultra-fine grained materials. Scripta Materialia. 1996; 35(2):143-146. http://dx.doi.org/10.1016/13596462(96)00107-8.

8. Johnson W and Kudo H. The mechanics of metal extrusion. Manchester: Manchester University Press; 1962.

9. Kudo H. Some analytical and experimental studies of axisymmetric cold forging and extrusion - I. International Journal numerically derived formation of a dead zone for material plastic flow in Figure 5.

Also the increase of ECAE pressure and decrease of total plastic shear resulting from an increase in friction during ECAE through a Segal $2 \theta$-die is well predicted.

The numerical estimation shows that the relative divergence of results $\delta\left(\gamma_{\mathrm{S}}\right)$ for two-way accumulated plastic shear $\gamma_{\mathrm{S}}$ calculations in the range of friction factor values $0 \leq m \leq 1$ is not more than $5.337 \%$ for $2 \theta=90^{\circ}, 3.662 \%$ for $2 \theta=105^{\circ}$, and $5.323 \%$ for $2 \theta=120^{\circ}$. Thus the maximum disagreement in summary shear does not exceed $5.337 \%$ for $90^{\circ} \leq 2 \theta \leq 120^{\circ}$.

Both theories predict significant decrease in $p / 2 k$ and $\gamma_{\mathrm{s}}$ when the $2 \theta$ angle increases from $60^{\circ}$ to $135^{\circ}$. Increasing friction factor $m$ leads to rise of the extrusion punching pressure and to a remarkable decrease in total plastic shear $\gamma_{\mathrm{S}}$. So the upper bound (UBM) results for accumulated plastic shear $\gamma_{\mathrm{S}}$ based on discontinuous velocity field (DVF) are in good agreement with classical Segal's slip line solution (SLM) for $0 \leq m \leq 1$.

The proposed upper bound approach can be applied to further analysis of ECAE with angular dies of more complex geometries.

of Mechanical Sciences. 1960; 2(1-2):102-127. http://dx.doi. org/10.1016/0020-7403(60)90016-3.

10. Laptev AM. Upper bound analysis of equal channel angular extrusion. In: Laptev AM, Perig AV, Kakavas PA, Anyfantis KN and Erfort YA. Proceedings of the 8th International Conference Research and Development in Mechanical Industry (RaDMI); 2008; Užice, Serbia. Kruševac: Institute IMK; 2008. p. 236240. CD-ROM. Available from: <http://orbit.dtu.dk/fedora/ objects/orbit:112332/datastreams/file_9586477/content>.

11. Laptev AM, Perig AV and Vyal OY. Analysis of Equal Channel Angular Extrusion by Upper Bound Method and Rigid Blocks Model. Materials Research. 2014; 17(2):359-366. http://dx.doi. org/10.1590/S1516-14392013005000187.

12. Luri R, Luis CJ, León J and Sebastián MA. A New Configuration for Equal Channel Angular Extrusion Dies. Journal of Manufacturing Science and EngineeringTransactions of the ASME. 2006; 128(4):860-865. http://dx.doi. org/10.1115/1.2194555.

13. Luis Pérez CJ and Luri R. Study of the ECAE process by the upper bound method considering the correct die design. Mechanics of Materials. 2008; 40(8):617-628. http://dx.doi. org/10.1016/j.mechmat.2008.02.003.

14. Medeiros N, Moreira LP, Bressan JD, Lins JFC and Gouvêa JP Sensitivity analysis of the ECAE process via $2 \mathrm{k}$ experiments design. Matéria. 2010; 15(2):208-217.

15. Milind TR and Date PP. Analytical and finite element modeling of strain generated in equal channel angular extrusion. International Journal of Mechanical Sciences. 2012; 56(1):2634. http://dx.doi.org/10.1016/j.ijmecsci.2011.12.002.

16. Narooei $\mathrm{K}$ and Karimi Taheri A. A new model for prediction the strain field and extrusion pressure in ECAE process of circular cross section. Applied Mathematical Modelling. 2010; 34(7):1901-1917. http://dx.doi.org/10.1016/j. apm.2009.10.008. 
17. Narooei K and Karimi Taheri A. Strain field and extrusion load in ECAE process of bi-metal circular cross section. Applied Mathematical Modelling. 2012; 36(5):2128-2141. http://dx.doi. org/10.1016/j.apm.2011.08.008.

18. Narooei $\mathrm{K}$ and Taheri AK. Using of Bezier formulation for calculation of streamline, strain distribution and extrusion load in rectangular cross section of ECAE process. International Journal of Computational Methods. 2013; 10(3):1350005. http://dx.doi.org/10.1142/S0219876213500059.

19. Paydar MH, Reihanian M, Ebrahimi R, Dean TA and Moshksar MM. An upper-bound approach for equal channel angular extrusion with circular cross-section. Journal of Materials Processing Technology. 2008; 198(1-3):48-53. http://dx.doi. org/10.1016/j.jmatprotec.2007.06.051.

20. Perig AV. Mechanics of the equal channel angular extrusion. In: Perig AV, Kakavas PA, Anyfantis KN and Laptev AM. Proceedings of the 36 International Summer SchoolConference "Advanced Problems in Mechanics"; 2008; St. Petersburg. St. Petersburg: Institute for Problems in Mechanical Engineering of Russian Academy of Sciences; 2008. p. 513-520. Available from: <http://apm-conf.spb.ru/old/2008/ apm2008_proceedings.pdf $>$.

21. Perig AV, Laptev AM and Kakavas PA. Upper bound analysis of equal channel angular extrusion: two-Parameter rigid blocks approach and numerical verification. In: Oñate E, Owen DRJ and Suárez B, editors. Proceedings of the X International Conference on Computational Plasticity (COMPLAS X) "Fundamentals and Applications"; 2009; Spain. Barcelona: CIMNE; 2009. CD-ROM. Available from: <http://congress. cimne.com/complas09/proceedings/pdfs/p379>.

22. Perig AV, Laptev AM, Golodenko NN, Erfort YA and Bondarenko EA. Equal channel angular extrusion of soft solids. Materials Science and Engineering A. 2010; 527(16-17):37693776. http://dx.doi.org/10.1016/j.msea.2010.03.043.

23. Perig AV, Zhbankov IG, Matveyev IA and Palamarchuk VA. Shape Effect of Angular Die External Wall on Strain Unevenness during Equal Channel Angular Extrusion. Materials and Manufacturing Processes. 2013; 28(8):916-922.
24. Perig AV, Zhbankov IG and Palamarchuk VA. Effect of Die Radii on Material Waste during Equal Channel Angular Extrusion. Materials and Manufacturing Processes. 2013; 28(8):910-915.

25. Perig AV, Tarasov AF, Zhbankov IG and Romanko SN. Effect of $2 \theta$-Punch Shape on Material Waste during ECAE through a 20-Die. Materials and Manufacturing Processes. 2014. In press. http://dx.doi.org/10.1080/10426914.2013.832299.

26. Perig AV and Laptev AM. Study of ECAE mechanics by upper bound rigid block model with two degrees of freedom. Journal of the Brazilian Society of Mechanical Sciences and Engineering. 2014; 36(3):469-476. http://dx.doi.org/10.1007/ s40430-013-0121-z

27. Perig AV and Golodenko NN. CFD Simulation of ECAE through a Multiple-Angle Die with a Movable Inlet Wall. Chemical Engineering Communications. 2014; 201(9):12211239. http://dx.doi.org/10.1080/00986445.2014.894509.

28. Perig AV and Golodenko NN. CFD 2D Simulation of Viscous Flow during ECAE through a rectangular Die with Parallel Slants. International Journal of Advanced Manufacturing Technology. 2014; 74(5-8):943-962. http://dx.doi.org/10.1007/ s00170-014-5827-2.

29. Reihanian M, Ebrahimi R and Moshksar MM. Upper-bound analysis of equal channel angular extrusion using linear and rotational velocity fields. Materials \& Design. 2009; 30(1):2834. http://dx.doi.org/10.1016/j.matdes.2008.04.059.

30. Segal VM. Materials processing by simple shear. Materials Science and Engineering A. 1995; 197(2):157-164. http:// dx.doi.org/10.1016/0921-5093(95)09705-8.

31. Segal VM. Slip line solutions, deformation mode and loading history during equal channel angular extrusion. Materials Science and Engineering A. 2003; 345(1-2):36-46. http:// dx.doi.org/10.1016/S0921-5093(02)00258-7.

32. Talebanpour B and Ebrahimi R. Upper-bound analysis of dual equal channel lateral extrusion. Materials \& Design. 2009; 30(5):1484-1489. http://dx.doi.org/10.1016/j. matdes.2008.08.006. 


\section{Nomenclature}

$a$ is the channel width of the ECAE die, [m];

$2 \theta$ is the channel intersection angle of the ECAE die, [deg];

The $2 \theta$-die is the ECAE die with channel intersection angle $0^{\circ}<2 \theta<180^{\circ}$;

$h$ is the height (length) of the dead zone, [m];

$x=h / a$ is the relative height (the relative length) of the dead zone, where $0 \leq x \leq \cot (\theta)$;

$\langle\operatorname{grad}(\Delta \alpha)\rangle$ is the averaged value of gradients of macroscopic rotation within the workpiece material, $[\mathrm{rad} / \mathrm{m}]$;

$p$ is the Perig-derived ECAE punching pressure, obtained by the upper bound (UBM) theory with rigid blocks introduction, $[\mathrm{Pa}]$;

$\sigma_{\mathrm{s}}$ is the flow stress of the workpiece material, $[\mathrm{Pa}]$;

$k$ is the plastic constant of the workpiece material, [Pa], where $k=\sigma_{S} / \sqrt{3}$ (in this case we assume the 2D plastic flow of the workpiece material, where the workpiece inlet and outlet die channels have rectangular cross sections);

$p / 2 k$ is the dimensionless (relative) Perig-derived ECAE punching pressure, obtained by the upper bound (UBM) theory with rigid blocks introduction;

$(p / 2 k)_{\text {segal }}$ is the dimensionless (relative) Segal-derived ECAE punching pressure, obtained by the slip line (SLM) theory; $m$ is the dimensionless plastic friction factor in the Siebel (Tresca) friction law, where $0 \leq m \leq 1$;

$1_{\mathrm{AC}}=1_{\mathrm{DB}}$ are the lengths of friction zones;

$V_{1}$ is the workpiece material velocity in the inlet channel of the ECAE die, $[\mathrm{m} / \mathrm{s}]$;

$V_{3}$ is the workpiece material velocity in the outlet channel of the ECAE die, $[\mathrm{m} / \mathrm{s}]$;

$l_{\mathrm{i}-\mathrm{j}}$ are the lengths of common boundaries or interface joints for rigid blocks $\mathrm{i}$ and $\mathrm{j}$ within the rigid blocks partitioning scheme, where $i, j=1,2,3$;

$\left[V_{\mathrm{i}-\mathrm{j}}\right]$ are the relative sliding velocities for blocks $\mathrm{i}$ and $\mathrm{j}$, where $\mathrm{i}, \mathrm{j}=1,2,3$;

$V_{i-j}^{n}$ is a velocity component orthogonal to a discontinuity line $l_{\mathrm{i}-\mathrm{j}}$, where $\mathrm{i}, \mathrm{j}=1,2,3$;

$\gamma$ is the dimensionless value of plastic shear at the inclined discontinuity line, where $\gamma=\gamma_{i-j}=\left[V_{i-j}\right] / V_{i-j}^{n}$, and i, $\mathrm{j}=1,2,3$;

$R_{U B M}=\gamma_{s}$ is the Perig-derived dimensionless value of total accumulated ECAE plastic shear, obtained by the upper bound (UBM) theory with rigid blocks introduction, where $\gamma_{S}=2 \gamma$,

$R_{S L M}=\gamma_{\text {Segal }}$ is the Segal-derived dimensionless value of total accumulated ECAE plastic shear, obtained by the slip line (SLM) theory;

$\varepsilon_{e}$ is the equivalent plastic strain during ECAE;

$\delta$ is the relative dimensionless divergence (disagreement) of results, [\%];

SPD is Severe Plastic Deformation;

ECAP is Equal Channel Angular Pressing;

ECAE is Equal Channel Angular Extrusion;

UBM is Upper Bound Method;

DVF is Discontinuous Velocity Field;

DOF is Degree of Freedom;

$\mathrm{DZ}$ is Dead Zone;

SLM is Slip Lines Method. 